\title{
Empirical Investigation of Safety Practices in the Large Scale Construction Industry in Sri Lanka
}

\author{
Bhagyani, $A A B$ and Kottawatta, $H$
}

\begin{abstract}
Area of the Study

This study attempts to identify the current safety issues in the construction field, identify effectiveness of the safety strategies used by the construction field and to propose effective and preventive safety strategies.
\end{abstract}

\section{Problem of the Study}

The research problem addressed under this study is to identify the real safety practices of the construction industry in Sri Lanka.

\section{Method of the Study}

The existing literature, experts' opinions and the authors' experience were reviewed to find the safety issues and safety strategies. Based on knowledge gained from these sources, a detailed questionnaire was developed aiming the main objective of identifying safety strategies used in the industry. For this study 40 ongoing large building construction sites were selected as the survey sample. In proposing effective and preventive safety strategies, the Pearson's Correlation between identified severe issues and safety strategies was used.

\section{Findings of the Study}

Poor safety documentation, lesser safety education and awareness and lesser provision of resources and insurance policies were identified as most severe issues in the construction industry in Sri Lanka. Safety strategies like safety signs and symbols, prohibition of unhealthy drugs, alcohol at workplace and providing safety manuals, handouts and first aid toolkits to workers and management were identified as most effectively practicing safety strategies in large scale construction industry in Sri Lanka. To overcome the current severe safety issues four effective and preventive safety strategies; safety specialized training, accident Insurance policy, safety planning; pre project and pre task and safety meetings were proposed considering the strong positive relationship with safety issues that had been identified.

\section{Conclusion of the Study}

In order to avoid or to minimize the safety issues that are severe in the construction industry Sri Lanka, implementation of above strategies become utmost important because they would prevent the most critical safety issues that are experienced by the large scale construction industry in Sri Lanka. Integration of all these can be produced skilled and self-disciplined personnel into this field. Thereby, the industry can establish the safety culture in construction sites in Sri Lanka.

Keywords: Construction Industry, Safety Issues, Safety Strategies 


\section{Introduction}

The working world has been facing challenges and demands at a fast pace making the requirement of a new dynamic approach to management in which human resources are an integral and key factor in maintaining and achieving competitiveness and high organizational results. As elaborated by Goncalves and Neves (2012) this reality has led researchers to look into the Human Resource Management (HRM) practices that are associated with a better organizational performance in working world.

According to Raj and Kothai (2014) HRM is the management process of an organization's workforce, or human resources. As indicated by Opatha (2009) HRM is a combination of 18 functions. Among those functions Health and Safety Management is an important function for all types of organizations that are accountable for protecting and optimizing the functionality of human resources to achieve success and progress of success to the organizations. In fact Health and Safety Management will ensure the accomplishment of five strategic goals of HRM explained by Opatha (2009); improved employee productivity, employee development, increased quality of work life, legal compliance and customer compliance.

According to Industrial Accident Prevention Association (2007), the term occupational safety is defined as the maintenance of a work environment that is relatively free from actual or potential hazards that can injure employees (IAPA 2007). In regard to construction, ensuring workplace safety is not an easy task. According to Carter and Smith (2006) the construction industry's safety record has always been poor and it remains one of the most dangerous industries in which to work. It is needless to say that construction is a high hazard industry that comprises a wide range of activities involving construction, alteration and/or repair.

Construction sector in Sri Lanka has tremendously grown in the recent past and construction has developed into an important base of the national economy. The end of the island's ethnic conflict in 2009 has revived the economic activity and resulted in a strong focus on infrastructure development (IMaCS Research \& Analytics 2011). Department of Census and Statistics (2012) data shows that Construction sector GDP stood at Rs. 247 b (US\$ 1.9 b) in 2012 while the sector recorded a growth of $21.6 \%$ in 2012 compared to the GDP growth of $6.4 \%$ and industry sector growth of $10.3 \%$. As elaborated in IMaCS Research and Analytics (2011) acceleration of ongoing projects such as for development of power sector including mega projects and road development including expressways, inter-regional national highways likely to generate large demand for companies in the construction industry.

As elaborated by Carter and Smith (2006) in general, the work environment in the construction industry is more hazardous than in other industries. According to many authors in other countries, this is mainly due to the potential nature for serious accidents and health hazards by heavy use of large equipment, dangerous tools, and hazardous materials (Abudayyeh et al. 2006). 
According to Hassanin and Hanna (2007) large contractors in the sense they tend to have a high degree of safety awareness, particularly in terms of their understanding of the concepts and notions of safety. Thus in case of this study it will provide a clear image about the real practices of safety environment in Sri Lanka. As indicated by Jain (2007) many safety investigators have addressed the saving benefits of managing safety. Langford et al. (2000) had found that for every dollar spent on accident prevention there are multiple times dollars savings in accidents which will not occur. In other words the long term benefits of employing an aggressive safety practices which emphasizes safer work practices may outweigh the costs of implementation and management (Hassanein \& Hanna 2007).

\section{Problem Background and Problem of the Study}

With consideration of worldwide context, among all industries, construction has the highest rate of accidents, including deaths and disabling injuries (Koehn et al. 1995; Fang et al. 1999; Ahmed et al. 2000). As cited in Korones' (2013) classification of dangerous jobs, construction workers are also included (Kottawatta 2013). Also the ILO estimates that two million women and men die each year as a result of occupational accidents and work-related illnesses (International Labour Organization 2009). As cited in Lopez-Valcarcel (1996) although it is difficult to quantify labour accidents on a global scale, a study by LopezValcarcel estimated that approximately 350,000 workers die every year due to labour accidents. Of these accidents, 60,000 occur in the construction industry worldwide (Priyadarshani et al. 2013).

According to the statistics of Health and Safety Executive (2013) Construction accounted for $5 \%$ of the employees in Great Britain and 6\% of them had reported injuries to employees. Among them $27 \%$ are fatalities, $10 \%$ major and $5 \%$ of them are over seven day injuries. The rate of fatal injury per 100000 construction workers in Britain was 1.9 in 2012/13 compared with a five year average of 2.3 . In 2012/13, $26 \%$ of all fatal injuries to workers were in construction and it accounts for the greatest number of fatal injuries of the industry sections.

According to Sawacha et al. (1999) general accidents at work occur either due to lack of knowledge, training or supervision, lack of means to carry out a task safely, errors in judgment, carelessness, laziness or total irresponsibility. In addition, the lack of a controlled working environment and the complexity and diversity of the sizes of organisations have an effect on safety performance in the industry (Sawacha et al. 1999).

As Abudayyeh et al. (2006) explains construction injuries have a direct impact on the individuals involved in construction as well as on the work itself. Impacts include personal suffering of the injured worker, construction delays and productivity losses, higher insurance premiums that result from injuries, and the possible liability suits for all parties involved in the project. There are many other indirect impacts such as revenue losses on the part of the owner for late project delivery and reduced morale of the workforce (Abdelhamid \& Everett 2000). In fact as elaborated by Rubio et al. (2005) occupational accidents in the construction industry cause economic and social problems in organizations, as well as countries. 
When it comes to Sri Lanka our GDP clearly shows that the construction sector is growing at an increasing rate while the number of fatal accidents is also increasing at a higher rate than that (De Silva \& Wimalaratne 2012). As illustrated by Halwathura (n.d.) lack of attention is paid on health and safety aspects with the progress of the industry.

In Sri Lanka, as in other countries, the extent of construction accidents is more severe when compared to other industries (Rameezdeen et al. 2003). The nature of the work at construction sites in Sri Lanka is labour intensive and heavily depended on the workforce of skilled and unskilled with different educational backgrounds and hence has high potential for personal injuries (Rameezdeen et al. 2003; Gunawardena \& Priyangika 2005). According to IMaCS Research \& Analytics (2011) almost $97 \%$ of total persons employed were males with $75 \%$ falling in the $25-45$ age groups while $52 \%$ were with experience of less than five years.

De Silva et al. (2008) found that inadequate safety precautions, non-implementation of rules, limited funds, deficient knowledge and unqualified officers cause unexpected accidents in the construction industry in Sri Lanka. Furthermore, according to an annual report published in 2012 by Institute of Construction Training and Development (ICTAD), the safety practices that are adopted at construction sites are far below acceptable standards (ICTAD, 2012). Additionally, the low educational level of many construction workers is a barrier to improving safety at construction sites in Sri Lanka (De Silva \& Wimalaratne 2012).

Inadequate or absence of safety management systems, regulations, policies, resources and commitment have been cited in many instances as reasons for poor OSH performance in the construction industry. Many practical efforts were taken to improve OSH in the past. However, as cited in Gunawardena and Priyangika (2005) Sri Lanka is considered to be one of the most vulnerable countries, and is ranked at a low level for Occupational Safety and Health performance due to lack of improvement measures (De Silva and Wimalaratne 2012).

Though efforts have been made to address this problem, the results are far from satisfactory as construction accidents continue to dominate (Priyadarshani et al. 2013). Despite programs implemented by government authorities and the initiatives of private companies, the number of construction accidents remains alarmingly high in construction industry (Teo et al. 2005). So it is evident that these efforts are not sufficient to control the occurrence of unsafe acts and unsafe conditions at construction sites in Sri Lanka and whole world as well.

\section{Research Framework}

Safety issues are the common workplace concerns that workplace accidents can be prevented if everyone in the company was aware of and if worked together to make the workplace safer. The safety issues pertaining in the construction field are categorized under 5 factors (De Silva and Wimalaratne 2012) as follows: 
1. Management Commitment (De Silva and Wimalaratne, 2012)

a Lack of consideration by the top management (Ahamed et al. n.d.; Abudayyeh et al. 2006)

b Poor allocation for the personal protective equipment (Ahamed et al. n.d.)

c Financial Constraints on safety (Ahamed et al. n.d.)

d Poor safety awareness of top management (Tam et al. 2004)

2. Resources and Insurance Policies (De Silva and Wimalaratne 2012)

a No proper safety policy (Ahamed et al. n.d.)

b Unawareness of health and safety policy (Halwathura n.d.)

c Lack of health and safety instruments (Halwathura n.d.)

d Reactive management procedures on safety (Abdelhamid and Everett 2000)

e Lack of information about injury management on display (Abudayyeh et al. 2006)

f No proper injury management procedure (Tam et al. 2004)

3. Safety Documentation (De Silva and Wimalaratne 2012)

a Lesser provision of safety booklets (Sawacha et al.1999)

b Never encouraged to report safety incidents (Priyadarshani et al. 2013)

c Safety incident reports don't get followed up (Priyadarshani et al. 2013)

4. Controlling the Workers Safety Behavior (De Silva and Wimalaratne 2012)

a Ignorance on safety matters by the site Engineer and other technical staff (Ahamedetal n.d.)

b Poor quality of construction materials and equipment (Priyadarshani et al. 2013; Cheng et al. 2004)

c Lack of attention to safety management by main contractors/project managers (Priyadarshani et al. 2013; Cheng et al. 2004)

d Poor safety awareness of project managers (Tam et al. 2004)

5. Safety Education and Awareness (De Silva and Wimalaratne 2012)

a Lack of facilities to train the workers (Ahamed et al. n.d.)

b Insufficient training on health and safety (Halwathura n.d.; Priyadarshani et al. 2013; Cheng et al. 2004; Abdelhamid and Everett 2000; Tam et al. 2004).

c Lack of technology, equipment and inspection by a qualified person (De Silva and Wimalaratne 2012)

d Poor site supervision (Halwathura n.d.)

This research with reference to literature, widely used 10 safety strategies that had been identified and they were named as Dimensions of Safety Strategies to analyze the effectiveness of those strategies in the large scale construction industry in Sri Lanka.

\section{$1 \quad$ Safety Meetings}

2 Involvement of Workers for Safety Decision Making

3 Accident Insurance Policy

$4 \quad$ Qualification of Safety Officer

5 Providing Safety Manuals handouts and First-aid Toolkits to Workers and Management

6 Safety Planning; pre project and pre task

7 Prohibition of Drugs and Alcohol
Cameron and Duff (2007), Hinze and Raboud (1988), Chan et al. (2010), Cheng et al. (2012), Hinze (2002), Jaselskis et al. (1996)

Hinze and Raboud (1988), Cameron and Duff (2007), Langford et al. (2000), Hassanein and Hanna (2007)

Teo et al. (2005), De Silva and Wimalaratne (2012), Hinze (2002), Poon et al. (2000)

Abudayyeh et al. (2006), Hinze and Raboud (1988), Chan et al. (2010), De Silva and Wimalaratne (2012), Wilson and Koehn (2000), Huang and Hinze (2006), Ahamed et al. (n.d.), Molenaar et al. (2009), Jaselskis et al. (1996)

Cameron and Duff (2007), Chan et al. (2010), Jannadi (1995), De Silva and Wimalaratne (2012)

Aksorn and Hadikusumo (2008), De Silva and Wimalaratne (2012), Kyoo-Jin and David (2006)

De Silva and Wimalaratne (2012), Hinze and Gambatese (2003) 
ISSN: $2012-7227$

at Work Place

8 Paying Allowance for Workers who Work at Risks

$9 \quad$ Safety Signs and Symbols

10 Safety Specialized Training
Aksorn and Hadikusumo (2008), Teo et al. (2005), Hinze and Gambatese (2003), Hinze and Wilson (2000), Ahamed et al. (n.d.), Molenaar et al. (2009), Jaselskis et al. (1996)

Chan et al. (2010), Jannadi (1995), De Silva and Wimalaratne (2012), Yoon et al. (2013)

Cameron and Duff (2007), Hinze and Raboud (1988), Chan et al. (2010),

Teo et al. (2005), Jannadi (1995), Hinze and Gambatese (2003), Abudayyeh et al. (2006)

\section{Method}

\section{Study Design}

According to Sekaran (2010) the goal of a descriptive study is to offer a profile or to describe relevant aspects of the phenomena of interest to the researcher from an individual, organizational, industry-oriented, or other perspective. The objectives of this study were; to identify the current safety issues in the construction field, to identify effectiveness of the safety strategies used by the construction field and to propose effective and preventive safety strategies. Research problem addressed under this study is to explore the real safety practices of the construction industry in Sri Lanka. As the study was conducted in natural environment where events normally occur, that is a non- contrived setting. No any artificial or contrived setting was created for the study. This study took over one month for the collection of data. The study will offer a snapshot of a single moment in that time and would not consider what happens before or after the snapshot is taken. The data for the study was collected within a particular time period and there was no subsequent extension of the research contemplated. Hence, this study was a cross sectional study. According to Sekaran (2010), unit of analysis refers to the level of aggregation of the data collected during the subsequent data analysis stage. The unit of the study was individual since data were gathered from a person from management level at each site.

The entire ongoing construction project sites in Sri Lanka listed in ICTAD (The Institute for Construction Training and Development) was the total population. When selecting the sample the convenience sampling method was used. Most construction projects in Sri Lanka have been listed in ICTAD (The Institute for Construction Training and Development) according to a grading scheme $(\mathrm{C} 1$ to $\mathrm{C} 10)$. According to that listing, large scale construction project sites are identified as those that are ranked above $\mathrm{C} 5$ grade. (i.e. C1, C2, C3, C4).In this research since safety practices of large scale construction industry are studied, only construction sites that were ranked above $\mathrm{C} 5$ grade was chosen according to the ICTAD ranking. The rationale of selecting the large contractors was to select the most experienced and knowledgeable experts in this field. Further, they are believed to be following better OSH standards due to their resources to do so (Hassanein and Hanna 2008). Then 40 ongoing large construction sites were selected as the survey sample referring to conveniently availability. A person from the management level was selected from each site for the interview. 
Out of 40 respondents 22 were Site Engineers, 8 were Technical Officers and 6 were Project Managers, which is $55 \%, 20 \%$ and $15 \%$ of the total respectively. Also 3 Consultants and 1 Managing Director was contacted which amounts to $7.5 \%$ and $2.5 \%$ from the total sample respectively. And the 40 survey sample comprised 24 construction sites and 22 construction sites that employed less than 100 Direct and Indirect average number of workers respectively which amounts to $60 \%$ and $55 \%$ of total sample. 12 out of 40 construction sites employed among 100 - 300 average number of employees both directly as well as indirectly which is $30 \%$ in total. Also 4 among 40 construction sites and 6 among 40 construction sites which is $10 \%$ and 15\% employed more than 300 direct and indirect average numbers of persons respectively.

\section{Measures}

Data collection was structured in several steps. First, the existing literature, experts' opinions and the authors' experience were reviewed to find the pertaining safety issues and safety strategies in the industry. Next, based on knowledge gained from these sources, a detailed questionnaire was developed to be asked through telephone interviews aiming the main objective of identifying current safety issues in the construction industry and safety strategies used by the industry practitioners. The questionnaire was comprised of three sections. The first section covered general information on the respondent and construction projects, whereas the second section collected information regarding safety issues experienced. In the third section, it gathered information on the pre-identified Safety management strategies and their industry practice. Last section gathers information on injuries and safety hazards records. Some of the questions used in this research were well- accepted questions and the others are originally developed by the author referring to standard questionnaires. The practice or otherwise of each strategy in the industry was ascertained using three point Likert scale; "Agree, Neutral and Disagree". And the safety performance statistics data were also gathered by direct answers.

\section{Techniques of Data Analysis}

The data collected from the primary source were analyzed using the computer based statistical data analysis package, SPSS (version 16.0) for validity, reliability, and relationship testing. The data analysis included univariate and bivariate analyses.

\section{Results}

To investigate the current safety issues and effective safety strategies univariate analysis was used. The results are given in Table 1 and 2. 
ISSN: 2012-7227

Table 1: Current Safety Issues Distribution in the Construction Industry

\begin{tabular}{|c|c|c|c|c|c|c|c|}
\hline Issue category & $\mathrm{N}$ & Mean & Rank & Dimensions of Safety Issues & $\mathrm{N}$ & Mean & Rank \\
\hline \multirow{4}{*}{$\begin{array}{l}\text { Management } \\
\text { Commitment }\end{array}$} & \multirow{4}{*}{40} & \multirow{4}{*}{2.081} & \multirow{4}{*}{4} & Consideration by the top management & 40 & 2.2 & 16 \\
\hline & & & & $\begin{array}{l}\text { Allocation for the personal protective } \\
\text { equipment }\end{array}$ & 40 & 1.875 & 9 \\
\hline & & & & No Financial constraints on safety & 40 & 1.952 & 10 \\
\hline & & & & Safety awareness of top management & 40 & 1.975 & 11 \\
\hline \multirow{5}{*}{$\begin{array}{l}\text { Resources and } \\
\text { Insurance Policies }\end{array}$} & \multirow{5}{*}{40} & \multirow{5}{*}{1.935} & \multirow{5}{*}{3} & Proper safety policy & 40 & 2.2 & 16 \\
\hline & & & & Awareness of health and safety policy & 40 & 1.85 & 7 \\
\hline & & & & $\begin{array}{l}\text { Proactive management procedures on } \\
\text { safety }\end{array}$ & 40 & 2.2 & 16 \\
\hline & & & & $\begin{array}{l}\text { Information about injury management on } \\
\text { display }\end{array}$ & 40 & 1.575 & 2 \\
\hline & & & & Proper injury management procedure & 40 & 1.825 & 5 \\
\hline \multirow{3}{*}{$\begin{array}{l}\text { Safety } \\
\text { Documentation }\end{array}$} & \multirow{3}{*}{40} & \multirow{3}{*}{1.742} & \multirow{3}{*}{1} & High provision of safety booklets & 40 & 1.825 & 5 \\
\hline & & & & Encouragement to report safety incidents & 40 & 1.7 & 3 \\
\hline & & & & Safety incident reports get followed up & 40 & 1.725 & 4 \\
\hline \multirow{4}{*}{$\begin{array}{lr}\text { Controlling } & \text { the } \\
\text { Workers } & \text { Safety } \\
\text { Behavior } & \end{array}$} & \multirow{4}{*}{40} & \multirow{4}{*}{2.244} & \multirow{4}{*}{5} & $\begin{array}{l}\text { Care on safety matters by the site } \\
\text { Engineer and other technical staff }\end{array}$ & 40 & 2.375 & 20 \\
\hline & & & & $\begin{array}{l}\text { Good quality of construction materials } \\
\text { and equipment }\end{array}$ & 40 & 2.15 & 15 \\
\hline & & & & $\begin{array}{l}\text { Attention to safety management by main } \\
\text { contractors/project managers }\end{array}$ & 40 & 2.125 & 14 \\
\hline & & & & $\begin{array}{l}\text { Good safety awareness of project } \\
\text { managers }\end{array}$ & 40 & 2.3 & 19 \\
\hline \multirow{4}{*}{$\begin{array}{l}\text { Safety Education } \\
\text { and Awareness }\end{array}$} & \multirow{4}{*}{40} & \multirow{4}{*}{1.919} & \multirow{4}{*}{2} & Facilities to train the workers & 40 & 1.525 & 1 \\
\hline & & & & Sufficient training on health and safety & 40 & 1.85 & 7 \\
\hline & & & & $\begin{array}{l}\text { Good enough technology, equipment } \\
\text { and inspection by a qualified person }\end{array}$ & 40 & 2.1 & 13 \\
\hline & & & & Excellent site supervision & 40 & 2.00 & 12 \\
\hline
\end{tabular}

Table 2: Effectiveness of Safety Strategies Distribution in the Construction Industry

\begin{tabular}{|l|l|l|l|l|}
\hline & Safety Strategies & N & Mean & Rank \\
\hline & & & & \\
\hline 1 & Safety meetings & 40 & 1.863 & 5 \\
\hline 2 & Involvement of workers for safety decision making & 40 & 2.142 & 9 \\
\hline 3 & Accident Insurance policy & 40 & 1.763 & 4 \\
\hline 4 & A qualified safety officer & 40 & 1.875 & 6 \\
\hline 5 & $\begin{array}{l}\text { Providing Safety manuals, handouts and first aid toolkits to workers and } \\
\text { management }\end{array}$ & 40 & 1.744 & 3 \\
\hline 6 & Safety Planning; Pre project and pre task & 40 & 2.000 & 7 \\
\hline 7 & Prohibition of unhealthy drugs and alcohol at work place & 40 & 1.713 & 2 \\
\hline 8 & Paying a risk allowance for the workers who work at risk & 40 & 2.150 & 10 \\
\hline 9 & Safety signs and symbols & 40 & 1.250 & 1 \\
\hline 10 & Safety orientation programs & 40 & 2.042 & 8 \\
\hline
\end{tabular}


According to the data analysis on current safety issues following were identified as safety issues in the construction industry.

\section{Severe Safety Issues}

a. Lack of facilities to train workers

b. Lesser information about injury management on display

c. Less encouragement to report safety incidents

d. Lesser provision of safety booklets

e. Absence of proper injury management procedure

f. Insufficient training given on health and safety

g. Unawareness among the construction workers regarding the health and safety policy

h. Poor allocation of Personal Protective Equipment

i. Financial constraints on safety

j. Poor safety awareness of Top management

\section{Major Safety Issues}

a. Poor site supervision

\section{Minor Safety Issues}

b. Lack of technology, equipment and inspection by a qualified person

c. Lack of Attention to safety management by main contractors/ project managers

d. Poor quality of construction materials and equipment

e. Lack of consideration by the top management

f. No proper safety policy

g. Proactive management procedure on safety

h. Poor safety awareness of Project managers

i. Ignorance on safety matters by the site engineer and other technical staff

According to data analysis on safety strategies following were identified in the way that are practiced within the construction industry Sri Lanka.

\section{Excellent effectively practiced Safety Strategies}

a. Safety signs and symbols

b. Prohibition of unhealthy drugs and alcohol

c. Providing safety manuals, handouts and first aid toolkits

d. Accident insurance policy

e. Safety meetings

f. Having a qualified safety officer

\section{Good effectively practiced Safety Strategies}

a. Safety planning; pre-project and pre-task planning

\section{Poor effectively practiced Safety Strategies}

a. Safety specialized training programs

b. Involvement of the workers in safety decision making

c. Paying a "risk" allowance for the workers who work at risk

The bivariate analysis included the correlation analysis which was used to investigate relationships between severe safety issue categories and safety strategies. Pearson's Product Moment Correlation with one-tailed test of significance for that. The results are given in Table 3. 
Table 3: Correlation between Severe Safety Issue Categories and Safety Strategies

\begin{tabular}{|c|c|c|c|c|c|c|}
\hline & \multicolumn{2}{|c|}{$\begin{array}{l}\text { Safety } \\
\text { Documentation }\end{array}$} & \multicolumn{2}{|c|}{$\begin{array}{l}\text { Safety } \text { Education } \\
\text { and Awareness }\end{array}$} & \multicolumn{2}{|c|}{$\begin{array}{l}\text { Resources and } \\
\text { Insurance Policies }\end{array}$} \\
\hline & $\begin{array}{l}\text { Pearson } \\
\text { Correlation }\end{array}$ & Sig. & $\begin{array}{l}\text { Pearson } \\
\text { Correlation }\end{array}$ & Sig. & $\begin{array}{l}\text { Pearson } \\
\text { Correlation }\end{array}$ & Sig. \\
\hline Safety meetings & .596 & .037 & .986 & .037 & .786 & .037 \\
\hline $\begin{array}{l}\text { Involvement of workers for safety decision } \\
\text { making }\end{array}$ & .232 & .021 & .632 & .022 & .332 & .021. \\
\hline Accident Insurance policy & .768 & .001 & .668 & .001 & .968 & .001 \\
\hline A qualified safety officer & .678 & .041. & .878 & .031. & .478 & .041. \\
\hline $\begin{array}{l}\text { Providing Safety manuals, handouts and first } \\
\text { aid toolkits to workers and management }\end{array}$ & .478 & .041 & .764 & .002 & .638 & .041 \\
\hline Safety Planning; Pre project and pre task & .868 & .032 & .578 & .041. & .892 & .011 \\
\hline $\begin{array}{l}\text { Prohibition of unhealthy drugs and alcohol at } \\
\text { work place }\end{array}$ & .128. & .441 & .468 & .041. & .450 & .041 \\
\hline $\begin{array}{l}\text { Paying a risk allowancefor the workers who } \\
\text { work at risk }\end{array}$ & . 156 & .001 & .178 & 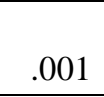 & .778 & .041 \\
\hline Safety signs and symbols & .101 & .024 & .757 & .031 & .778 & .001 \\
\hline Safety orientation programs & .845 & .003 & .978 & .021 & .894 & .021 \\
\hline
\end{tabular}

Since Safety Documentation, Safety Education and Awareness and Resources and Insurance Policies were identified as severe issue categories that are prevailing in the construction industry they were taken into consideration to measure the correlation with safety strategies. Following relationships were identified between severe issue categories and Safety Strategies.

1 Strong positive relationship

A Safety documentation 1) Safety meetings, 2) Accident Insurance Policy, 3) A qualified safety with officer, 4) Safety planning; pre-project and pre-task planning, 5) Safety specialized training

B Safety Education with 1) Awareness with Safety Meetings, 2) Awareness with Involvement of workers for Safety decision making, 3) Awareness with Accident Insurance Policy, 4) Awareness with Qualification of Safety Officer, 5) Awareness with Providing safety manuals handouts and toolkits to workers and management, 6) Awareness with Safety planning; pre project and pre task, 7) Awareness with Safety signs and symbols, 8) Awareness with Safety specialized Training

c Resources and 1) Policies with Safety Meetings, 2) Accident Insurance Policy, 3) Insurance Policies Providing safety manuals handouts and toolkits to workers and with management, 4) Safety planning; pre project and pre task, 5) Paying allowance for workers who work at risks, 6) Safety signs and symbols, 7) Safety specialized Training

2 Moderate positive relationship

a Safety documentation 1) Providing safety manuals, handouts and first aid toolkits with

b Safety education and 1) Prohibition of drugs and alcohol at workplace Awareness with

c Resources and 1) Involvement of the workers in safety decision making, 2) Involvement of 


\begin{tabular}{lll}
\hline \multicolumn{1}{c}{$\begin{array}{l}\text { Insurance Policies } \\
\text { with }\end{array}$} & $\begin{array}{l}\text { the workers in safety decision making with Qualification of safety officer, } \\
\text { 3) Prohibition of drugs and alcohol at workplace }\end{array}$ \\
\hline 3 & $\begin{array}{l}\text { Weak positive relationship } \\
\text { a Safety documentation } \\
\text { with }\end{array}$ & $\begin{array}{l}\text { 1) Involvement of the workers in safety decision making, 2) Prohibition of } \\
\text { drugs and alcohol at workplace, 3) Paying allowance for workers who work } \\
\text { at risk, 4) Safety signs and symbols }\end{array}$ \\
\hline b $\quad \begin{array}{l}\text { Safety education and } \\
\text { Awareness with }\end{array}$ & 1) Paying allowance for workers who work at risk \\
\hline
\end{tabular}

\section{Discussion and Conclusion}

Safety is an often ignored term in the Construction Industry and hence is not addressed to the required extent due to several reasons. The responsibility for providing and building the necessary safety culture, which goes beyond just preventing injuries in the construction sites, is a shared duty among all the stakeholders. In a construction site, it can be shared by the workforce and the management, which includes client, contractor and consultant and the government or the relevant authorities. However, all the responsible parties have neglected their share in building a safety culture and this has hampered improving performance. This study attempts to explore the real safety practices of large scale construction industry in Sri Lanka. First, the existing literature, expert opinions and the author experience were reviewed to find the prevailing safety issues and safety strategies in the industry. Next, based on knowledge gained from these sources, a detailed questionnaire was developed to be asked through telephone interviews aiming the main objective of identifying current safety issues in the construction industry and safety strategies used by the industry practitioners. Poor safety documentation, lesser safety educationand awareness and lesser provision of Resources and Insurance Policies were identified as most severe issues in the large scale construction industry in Sri Lanka. And safety strategies like Safety signs and symbols, Prohibition of unhealthy drugs, alcohol at workplace and Providing safety manuals, handouts and first aid toolkits to workers and management were identified as most effectively practicing safety strategies in large scale construction industry in Sri Lanka. The safety strategies that has a strongly positive relationship with severe safety issues were identified as Effective and preventive safety strategies to be proposed. To overcome the current severe safety issues four effective and preventive safety strategies; Safety specialized training, Accident Insurance policy, Safety planning; pre project and pre task and safety meetings were proposed at the end. Integration of all these can be produced skilled and self-disciplined personnel into this field. Thereby, the industry can establish the safety culture in construction sites in Sri Lanka.

\section{References}

i. Abdelhamid, TS \& Everett, JG 2000, 'Identifying root causes of construction accidents', Journal of Construction Engineering and Management, vol. 126, no.1, pp. 52-60.

ii. Abudayyeh, O, Federicks, TK, Butt, SE \& Shaar, A 2006, 'An investigation of management's commitment to construction safety', International Journal of Project Management, vol. 24, pp. 67-174. 
iii. Ahamed, MSS, Nafeel, AFM, Rishath, AAM \& Dissanayake, PBG n.d., 'Site Safety of Sri Lankan Building Construction Industry'.

iv. Ahmed, SM, Kwan, JC, Ming, FYW and Ho, DCP 2000, 'Site safety management in Hong Kong', Journal of Management in Engineering, vol. 16, no. 6, pp. 34-42.

v. Aksorn, T \& Hadikusumo, BHW 2008, 'Measuring effectiveness of safety programs in the Thai construction industry', Construction Management and Economics, vol. 26, pp. 409-421.

vi. Cameron, I \& Duff, R 2007, 'A critical review of safety initiatives using goal setting and feedback', Construction Management and Economics, vol. 25, pp. 495-508.

vii. Cameron, I, \& Duff, R 2007, 'Use of performance measurement and goal setting to improve construction managers' focus on health and safety', Construction Management and Economics, vol. 25, pp. 869-888.

viii. Carter, G \& Smith, SD 2006, 'Safety Hazard Identification on Construction Projects', Journal of Construction Engineering and Management, vol. 132, no. 2, pp. 197-205.

ix. Chan, DWM, Chan, APC \& Choi, TNY 2010, 'An empirical survey of the benefits of implementing pay for safety scheme PFSS in the Hong Kong construction industry', Journal of Safety Research, vol. 41, pp. 433-443.

x. Cheng, E.W.L., Li, H., Fang, D.P. and Xie, F. (2004). Construction safety management: An exploratory study from department of building and real estate. Construction Innovation, 4: 224-229.

xi. Cheng, EWL, Ryan, N \& Kelly, S 2012, 'Exploring the perceived influence of safety management practices on project performance in the construction industry', Safety Science, vol. 50, pp. 363-369.

xii. De Silva, N \& Wimalaratne, PLI 2012, 'OSH management framework for workers at construction sites in Sri Lanka', Engineering Construction and Architecture Management, vol. 19, no. 4, pp. 369-392.

xiii. De Silva, N, Rajakaruna, RWDWCAB \& Bandara, KATN 2008, 'Challenges faced by the construction industry in Sri Lanka', Conference Proceedings of the CIB International Conference in Building Education and Research Sri Lanka, pp. 10231032.

xiv. Department of Census and 2012, http://www.statistics.gov.lk/national accounts/National\%20Accounts\%20of\%20Sri\%20Lank a.pdf.

xv. Fang, DP, Song, HB \& Huang, XY 1999, 'Construction safety in China: Past, present and future', Conference Proceeding of the 2nd International Conference on Implementation of Safety and Health on Construction Site, Honolulu, Hawaii, 24-27 March.

xvi. Gonçalves, SP \& Neves, J 2012, 'The Link between Perceptions of Human Resource Management Practices and Employee Well-being at Work', Advances in Psychology Study, vol. 1, no. 1, pp. 31-39.

xvii. Gunawardena, ND \& Priyangika, LM 2005, 'Minimizing construction accidents through the integration of safety practices into ISO 9000 quality requirements', BuiltEnvironment, vol. 5, no. 2, pp. 28-33. 
xviii. Halwathura, RU n.d., 'Health and Safety Aspects in Building Construction Industry in Sri Lanka'.

xix. Hassanein, AAG \& Hanna, RS 2007, 'Safety Programs in Large-Size Construction Firms Operating in Egypt', Journal of SH \& E Research, vol. 4, no.1, pp. 1-33.

xx. Health and safety Executive in construction in Great Britain 2013, Work-related injuries and health. Available from: $<$ http://wwwhsegovuk/Statistics/industry/construction/indexhtm>. [06 October 2014].

xxi. Hinze, J \& Gambatese, J 2003, 'Factors That Influence Safety Performance of Specialty Contractors', Journal of Construction Engineering and Management, vol.129, pp. 159-164.

xxii. Hinze, J \& Raboud, P 1988, 'Safety on large building construction projects', Journal of Construction Engineering and Management, vol. 114, no. 2, pp. 286-293.

xxiii. Hinze, J \& Wilson, G 2000, 'Moving toward a zero injury objective', Journal of Construction Engineering and Management, vol.126, pp. 399-403.

xxiv. Hinze, J. (2002) Designing for Deconstruction Safety. Proceedings of the CIB Task Group 39 - Deconstruction Meeting, CIB Report, Publication 272, Karlsruhe, Germany.

xxv. Huang, X \& Hinze, J 2006, 'Owner's Role in Construction Safety: Guidance Model', Journal of Construction Engineering and Management, vo1. 32, pp. 174-181.

xxvi. Industrial Accident Prevention Association 2007, Glossary of Occupational Health \& Safety Terms, Available from: <wwwiapaca/pdf/iapa_glossarypdf>, [07 October 2014].

xxvii. Industrial Accident Prevention Association 2007, Glossary of Occupational Health \& Safety Terms, Available from: <wwwiapaca/pdf/iapa_glossarypdf>, [07 October 2014].

xxviii. Institute for Construction Training and Development 2012, Annual Report 2012, Available from: <http://wwwictadlkhtml >. [15 August 2014].

xxix. International Labour Organization 2009, World Day for Safety and Health at Work 2009: Facts on safety and health at work', International Labour Office, Geneva.

xxx. Jain, SK 2007, 'Meeting the Challenges in Industrial Safety Management in Construction Works', Available from: <http://wwwnpcilnicin/pdf/Endowment $\%$ 20lecture\%20by\%20CMD-1pdf>.[05 October 2014].

xxxi. Jannadi, MO 1995, 'Impact of human relations on the safety of construction workers', International Journal of Project Management, vol. 1, no. 6, pp. 383-386.

xxxii. Jaselskis, EJ, Anderson, SD \& Russell, JS 1996, 'Strategies for achieving excellence in Construction Safety performance', Journal of Construction Engineering and Management, vol.122, no. 1, pp. 61-70.

xxxiii. Koehn, E, Kothari, RK and Pan, C 1995, 'Safety in developing countries: Professional and bureaucratic problems', Journal of Construction Engineering and Management, vol. 121, no. 3, pp. 261-265.

xxxiv. Korones 2013, The 10 most dangerous jobs in America, http://www.zdnet.com/article/the-10most-dangerous-jobs-in-america/. 
xxxv. Kottawatta, KH 2013, Study Guide: Employee Health and Safety Management, Department of Human Resource Management, Faculty of Management studies and Commerce.

xxxvi. Kyoo-Jin \& David, L 2006, 'Scheduling-based risk estimation and safety planning for construction projects', Journal of Construction Engineering and Management, vol. 132, no. 6, pp. 625-635.

xxxvii. Langford, D, Rowlinson, S \& Sawacha, E 2000, 'Safety behavior and safety management: its influence on the attitudes of workers in the UK construction industry', Engineering, Construction and Architectural Management, vol.7, no. 2, pp.133-140.

xxxviii. López-Valcárcel, A. (1996). Seguridad y salud en el trabajo en el Marco de la Globalización de la Economía. Ministerio de Trabajo y Seguridad Social de España, Proyecto Regional Seguridad y Salud en el Trabajo en los procesos de integración y globalización, Documento de Trabajo 26, OIT [in Spanish].

xxxix. Molenaar, KR, Park, J \& Washington, S 2009, 'Framework for Measuring Corporate Safety Culture and Its Impact on Construction Safety Performance', Journal of Construction Engineering and Management, vol. 135, pp. 488-496.

xl. Opatha, HHDNP 2009, Human Resource Management: Personnel Colombo: Department of HRM - University of Sri Jayewardenepura.

xli. Poon, W.F., Ma, C.H. and Ho, K.L. (2000). Statistical analysis on factors in reducing construction site accident frequency rate in Hong Kong. Proceedings of the 6th Annual Conference of the Australian and New Zealand Association of Occupational Health and Safety Educators, Hong Kong, 341-355.

xlii. Priyadarshani, K, Karunasena, G \& Jayasuriya, S 2013, 'Construction Safety Assessment Framework for Developing Countries: A Case Study of Sri Lanka', Journal of construction in Developing Countries, vol. 18, no. 1, pp. 33-51.

xliii. Raj, BVA \& Kothai, PS 2014, 'Study on the Impact of Human Resource Management Practices in Construction Industry', The International Journal of Management, vol.3, no. 1, pp. 1-22.

xliv. Rameezdeen, R, Pathirage, C \& Weerasooriya, S 2003, 'Study of construction accidents in Sri Lanka', Built Environment, vol. 4, no. 1, pp. 27-32.

xlv. Rubio, MC, Menendez, A, Rubio, JC \& Martinez, G 2005, 'Obligations and responsibilities of civil engineers for the prevention of labor risks', Journal of Professional Issues in Engineering Education and Practice, vol. 131, no. 1, pp. 7075.

xlvi. Sawacha, E, Naoum, S \& Fong, D 1999, 'Factors affecting safety performance on construction sites', International Journal of Project Management, vol. 17, no. 5, pp. 309-315.

xlvii. Tam, CM, Zeng, SX \& Deng, ZM 2004, 'Identifying elements of poor construction safety management in China', Safety Science, vol. 42, pp. 569-586.

xlviii. Teo, EAL, Ling, FYY \& Chong, AFW 2005, 'Framework for project managers to manage construction safety', International Journal of Project Management, vol. 23, no. 4, pp. 329-341. 
xlix. Teo, EAL, Ling, FYY \& Ong, DSY 2005, 'Fostering safe work behavior in workers at construction sites', Engineering, Construction and Architectural Management, vol.12, no. 4, pp. 410-422.

1. Wilson MJ \& Koehn, EE 2000, 'Safety management: problems encountered and recommended solutions', Journal of Construction Engineering and Management, vol. 126, pp. 77-79.

li. Yoon, SJ, Lin, HK, Chen, G, Yi, S, Choi, J \& Rui, Z 2013, 'Effect of Occupational Health and Safety Management System on Work-Related Accident Rate and Differences of Occupational Health and Safety Management System Awareness between Managers in South Korea's Construction Industry', Safety and Health at Work, vol. 4, 201-209.

\section{Bhagyani, AAB}

Executive HR and Admin, Hirdaramani Industries (Pvt) Ltd, Kahathuduwa bamarathunge@yahoo.com

\section{Kottawatta, $\mathbf{H}$}

Professor, Department of Human Resource Management, University of Sri Jayewardenepura gimhana@sjp.ac.lk 